\title{
The Effects of Student Input on Homework Completion and Student Performance
}

\author{
Alisa Grimes* and Valerie Otero† \\ *Academy High School, Thornton, CO 80229 \\ †School of Education, University of Colorado, Boulder, CO 80309 USA
}

\begin{abstract}
Research has shown that student input and autonomy are positively correlated to motivation and agency. This study investigates the effect of student input on classroom procedures on homework completion rate. Two different classroom treatments were applied to two classes over the same term in an urban high school chemistry course. The first treatment involved eliciting student ideas regarding classroom structures surrounding homework that theoretically would lead to a greater homework completion rate. The second treatment (or control) involved the traditional, authoritative structures that had been in place-student ideas were not elicited about homework and therefore the teacher decided all structures and routines regarding homework. Our results suggest that structures derived with student input led to greater homework completion rates and to higher performances on the district assessment over the teacher decided homework condition. These results and their implications are discussed.
\end{abstract}

Keywords: homework, voice, community, participation, motivation, agency

\section{INTRODUCTION}

Research on the impact of homework on student achievement has demonstrated that there is a positive correlation between the amount of time spent on homework and academic achievement. [1] Studies have shown that students from lower income homes may have home life variables that account for lower homework completion rates. [2] In older students, some of these variables may include having to work outside the home in order to be a necessary contributor to their family's income. In this regard, the child's primary role may not be as a student. [3] In other situations, when parents have to work multiple jobs or undesirable hours, the older child may be responsible for taking care of younger siblings after school. In many of these circumstances, homework is not the primary focus of the student, resulting in a major difference between homes of low-income households and those coming from higher income households. Homework can perpetuate the social disparities between advantaged and disadvantaged students because low-income students often lack guidance and support necessary to prepare them for post-secondary endeavors. [4]

As a result, many teachers who serve these students are left with difficult decisions regarding homework. Some of these teachers choose to not give homework because they feel it will not get completed, or they make it worth a small percent of a student's overall grade. These students are not provided incentives to practice or develop their understanding of concepts outside of school.

As a result of doing their homework, benefits attained by students include increased academic achievement, higher test scores, an elevated view of their school, and a better image of themselves as learners. [5] Human development specialist Janine Bempechat stated, "As a pedagogical practice, homework plays a critical long-term role in the development of children's achievement motivation." Not only is there a positive correlation between homework and achievement, but also homework can increase the students' capacity to be responsible, motivated, and better with time management. [1]

In this study, we explored how changing classroom homework procedures impacted homework completion rates and academic achievement. Working from a theoretical perspective that views student autonomy as linked to motivation, we hypothesized that by increasing student autonomy and choice we might be able to impact homework completion rates. More specifically, we address the following questions: (i) how does the incorporation of students' input into classroom homework structures influence their homework completion rate and (ii) how does the teacher's treatment of homework influence overall student academic performance, both in their classroom and on their district assessments? 


\section{THEORETICAL PERSPECTIVE}

A review of the homework literature revealed homework studies frequently involve the effect of homework on course performance. One such study compared two groups of high school students that received identical instruction but one group was required to do homework while the other was not. The homework group outperformed the non-homework group $69 \%$ of the time. In addition while comparing achievement and time spent on homework, in 43 of the 50 high school students who self-reported spending more time on homework had an overall higher academic achievement. [6]

Another line of research on homework stems from work on student motivation. Findings from "choice theorists" indicate that student's motivation in completing any task, such as homework, may be attributed to autonomy and purpose. [7] This is consistent with other motivation theorists who have demonstrated that students' willingness to complete a task regardless of the challenge and their performance on these tasks can be attributed to students' sense of having choices. [8] Some researches argue that student input impacts homework performance because it provides opportunities for students to critically reflect on the homework purpose rather than simply doing it because they were told. [9]

Self-determination theorists argue that autonomy leads to intrinsic motivation, which allows students to understand the personal benefit of task completion. ${ }^{8}$ "The locus of responsibility has been defined as the teachers orientation towards autonomy and the degree to which teachers involve students in decision making" (Ryan \& Grolnick 1986). Students' sense of control appears to be a substantial factor in affecting student's engagement in learning. [10]

We drew on the findings described above to generate the hypothesis that if students are given a voice in how homework is managed in the classroom, they will be more likely to complete it, which would then result in higher overall performance. We take a socio-cultural perspective and view learning as a social practice. [11] Student choice is viewed as legitimate participation, which mediates belonging and contribution to a community. By viewing choice in classroom homework structures this way, we designed a study to test our hypothesis.

\section{RESEARCH CONTEXT}

This study consisted of 55 juniors in high school. These students attended Academy High School, a public STEM school with just over 350 students. This school is primarily composed of students who have been traditionally underrepresented in science. The district has defined itself as small-by-design with only 16 schools. See table 1 for demographic breakdown.

TABLE 1. Demographic composition of the school

\begin{tabular}{|l|l|l|l|l|l|}
\hline ELL & $\begin{array}{l}\text { Free \& } \\
\text { Reduced } \\
\text { lunch }\end{array}$ & Hispanic & White & Asian & $\begin{array}{l}\text { African } \\
\text { American }\end{array}$ \\
\hline $50 \%$ & $75 \%$ & $66 \%$ & $29 \%$ & $2 \%$ & $1 \%$ \\
\hline
\end{tabular}

Data were collected from two chemistry classes where $42 \%$ of students scored proficient or above in reading on the previous year's state test, 9\% scored proficient in math, and $26 \%$ scored proficient or above on the $10^{\text {th }}$ grade science test. According to the latest census data in the community, $17 \%$ of adults have a bachelor's degree, and $62 \%$ are not citizens of the United States.

\section{METHODOLOGY}

To investigate the research questions, different conditions were applied regarding homework routines in two chemistry classes over the same term. In the "student input" condition, the teacher elicited student suggestions for classroom homework proceedures. The teacher then compiled students' suggestions and the class voted on their top choices. The top choices that were instituted in the class were: class time to be used to review homework problems, the allowance of students to work with other students on their homework, all daily homework would be handed in and graded at the end of the week rather than daily (as was typical procedure), a "Thursday reminder" that homework was due the next day, and permission to use homework on classroom (not district) assessments. Students also suggested a penalty for late homeworkhomework turned in after Friday was deducted one letter grade per day late. These changes were instituted to classroom structure, however no other modifications were made to instructional practices.

For the "teacher directed" condition, homework was handled with traditional procedures, where it was assigned and graded on a daily basis, and students were penalized for late work each day, one letter grade deducted per day late. For this group, no class time was devoted to discuss homework problems, homework were not permitted to be used on assessments, and no reminders were given to students when homework was due. All homework for this class was due the day after it had been assigned. For this class, students' input regarding homework structures and routines were not solicited. Class instructional practices otherwise proceeded similarly as for the other group. 
In order to establish equivalence of groups, we compared students' previous year's standardized science test scores. The means were not statistically different at the .05 level. Therefore we assumed that the groups were equivalent to a reasonable degree.

\section{FINDINGS}

Overall, we found that students in the treatment group (student input) outperformed students in the control group (teacher decided) in homework completion, course grade, and district assessment. Figure 1 shows that the student input group completed more homework assignments than the teacher directed group $\mathrm{p} \leq 0.03$. Figure 2 shows that the student input group had a higher average course grade than the teacher directed group $\mathrm{p} \leq 0.001$ (this score included homework and class assessments).

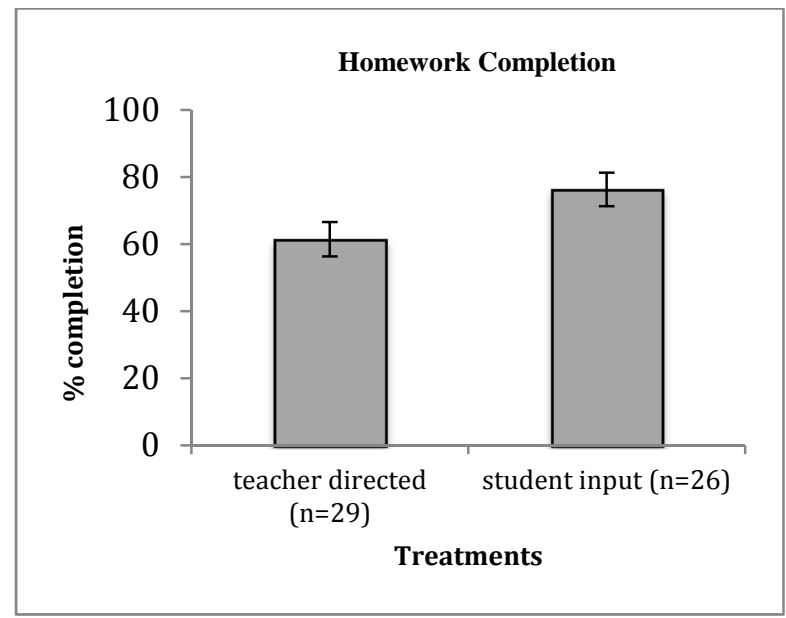

FIGURE 1. Homework completion rate

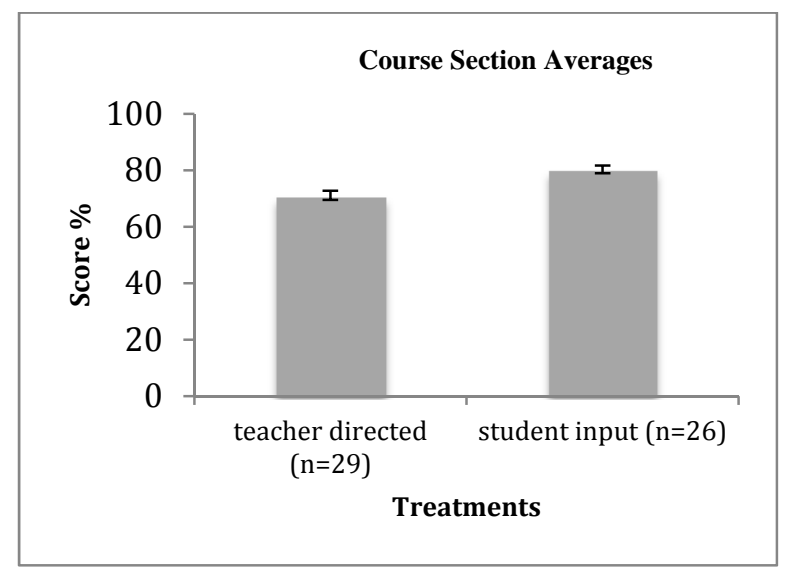

FIGURE 2. Course grade average

Course grade included homework scores as well as course assessment scores. In the student input group, students were allowed to use their homework on class assessments, so this may have influenced their assessment scores. Also, homework score was computed into their course grade score, and therefore, the higher course grade shown in figure 2 may be directly resulting from homework completion. In order to account for the influence of higher homework scores and use of homework on course assessments, we examined students' scores on the district assessment. Figure 3 shows that on the district assessment, the student input group scored statistically higher than the teacher directed group ( $p \leq 0.01$ ). The findings shown in figures 1 and 3 are consistent with the literature; they suggest that homework completion can lead to higher performance.

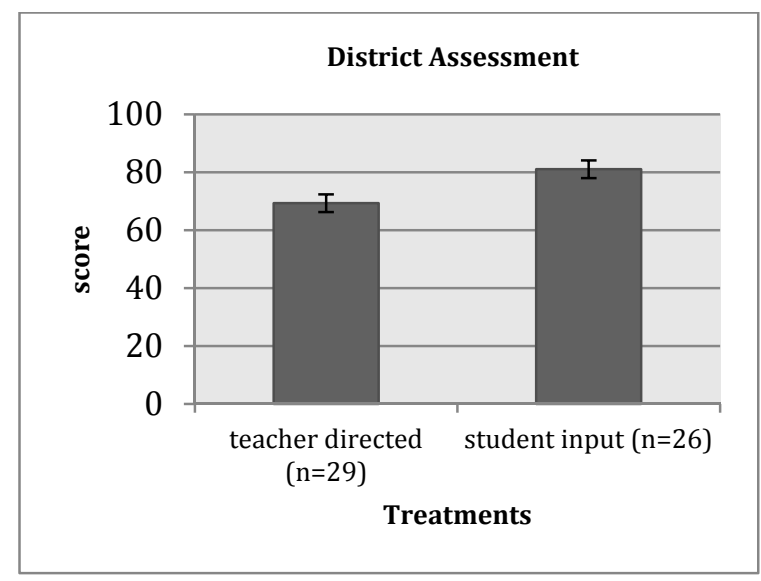

FIGURE 3. District assessment score

\section{CONCLUSIONS AND IMPLICATIONS}

The application of classic motivation theory leads to the conclusion that if students are given options about homework structures, intrinsic motivation may be enhanced, which leads to higher task completion rates. The findings from this study are well aligned with classic self-determination theory, suggesting that input and autonomy increase motivation to complete homework, and homework completion influences assessment performance.

We take issue however, with the notion of "intrinsic motivation," because it implies that the students possess (or do not posses) this quality of motivation. This classic view, while useful in many ways, does not account for human interactions with contextual features nor does it account for individuals' responses to contextual cues. Within sociocultural theoretical perspectives, motivation is seen a dynamic interaction within a complex system. This perspective views motivation as a contextual feature that is 
experienced by actors as they engage in various cultural practices of a community. According to this view of motivation, our study results suggest that student voice provided evidence of community membership for the actors, and now as members of a community, students behaved according to community norms. When learning is viewed as a social practice, the social and cultural aspects of learning cannot be overlooked. [12]

Using a sociocultural perspective on motivation, we argue that this study illustrates how small personal contributions can have a great influence on how a person situates his or herself within community activity. When students viewed the teacher as the authority figure who made all of the decisions, they may have situated themselves as visitors in a classroom belonging to the teacher. In this situation the students were not part of a community; they were outsiders. We conjecture that when students' contributions were explicitly sanctioned, their participation was given value and legitimacy; they were insiders. As insiders, students identify with community norms and practices. In this sense, motivation has to do with social organization and participation rather than solely with cognitive operations that drive action. [13] More specifically, we claim that the motivation of the students was a property of the system and not a property of the student. In our study we used two different classes filled with the same population of students and found that modification of the social organization of the system led to changed social practices.

The instructional implication brought to light from this research is that behavioral change may have more to do with social organization than we think. We often unconsciously correlate student performance and participation with properties of students. This could be problematic for teachers because teachers have no input on personal properties and dispositions of students. What teachers can influence is the social organization of the classroom. If student motivation and participation is as deeply connected to social organization as we conjecture, then teachers are in a better position to influence factors that lead to learning.

Many students come from home environments that are socially structured in ways that inhibit homework completion. By modifying the social structure of the classroom environment, the way students' manage that home environment seems to be influenced. Our data may suggest that a learning environment that values, respects, and utilizes the ideas and work of the students directly may benefit student performance. A learning environment that is dependent on student voices may help increase student performance and homework completion rates. In addition, these findings may highlight the importance of creating a democratic learning environment.

As illustrated through this study and previous research, high schools that have created a culture where students have a voice in their learning, everyone can be academically successful regardless of their differences; students are academically prosperous on even the most rigorous material. [14] Academic achievement is the highest when students feel like they have control over their academic successes and failures. As shown in this research, students may outperform students if they feel that they have a choice in the classroom constructs.

\section{ACKNOWLEDGMENTS}

We would like to appreciate the National Science Foundation for their continued support for helping teachers develop educational research with the NSF grant\# 0934921. In addition we would like to thank Mike Ross, Ben Van Dusen, Streamline to Mastery, and the school of education at the University of Colorado in Boulder for their continued support and guidance.

\section{REFERENCES}

1. P. Coutts. Theory into Practice 43 (3) 182-188 (2004).

2. E. Kralovec and J. Buell. The End of Homework: How Homework Disrupts Families, Overburdens Children, and Limits Learning (Beacon Press, 2000) p. 2

3. P. Hinchey. The Clearing House 69 (4) 242-245 (1996).

4. V. Lee and R. Ekstrom. Am. Ed. Res. 24 (2) 287 (1987).

5. AFT Classroom Tips: Assigning Effective Homework www.aft.org/tools4teachers

6. H. Cooper. Ed. Leadership 85-90 (1989).

7. D. Pink. Drive: The Surprising Truth about What Motivates Us (Riverhead Books, 2009) p. 3

8. E. Deci. Why We Do What We Do: Understanding SelfMotivation (Penguin Books, 1995) pp. 33-34

9. T. Malone and M. Lepper. Aptitude, Learning, and Instruction 3 (1987).

10. C. Ames. Journal of Educational Psychology 84 (3)

11. E. Wenger. Communities of Practice: Learning, Meaning, and Identity (Cambridge University Press, 1987).

12. N. Nasir. Math. Think. \& Learn. 4 (2 \& 3) 213-247 (2002).

13. K. O'Connor, A. Allen, Learning as the Social Organization of Futures, in W.R. Penuel \& K. O'Connor (Eds.), Yearbook of the National Society for the Study of Education, 108, 1: Learning research as a human science, pp. 160-175.

14. J. Gollub, M. Bertenthal, J. Labov, P. Curtis, Learning and Understanding: Improving Advanced Study of Mathematics and Science in U.S. High Schools (National Academy Press, 2003), p.127. 